\title{
Multidrug-resistant Staphylococci Found on Book Surfaces in East London Libraries
}

\author{
Adi Idris $^{1,2 *}$ and Ron R Cutler ${ }^{3}$ \\ ${ }^{1}$ Menzies Health Institute Queensland, School of Medical Science, Griffith University, Gold Coast, Queensland, Australia \\ ${ }^{2}$ PAPRSB Institute of Health Sciences, Universiti Brunei Darussalam, Brunei Darussalam \\ ${ }^{3}$ School of Biological and Chemical Sciences, Queen Mary University of London, London, United Kingdom
}

Received: December 11, 2017 / Accepted: December 11, 2017

\begin{abstract}
There is an increase in the presence of drug-resistant staphylococci outside of the nosocomial and healthcare setting. Although the presence of staphylococci has been studied in several public spaces, nothing is known on the presence of staphylococci in public libraries. Book surfaces from public libraries in the East London area, United Kingdom were swabbed and cultured and identity of the isolates determined by matrix-assisted laser desorption/ionization time of flight (MALDI-TOF) mass spectrometry (MS). Seven different staphylococcal species were identified by MALDI-TOF-MS analysis. This short study provides evidence of the presence of multidrug-resistant staphylococci in public libraries in the East London area.
\end{abstract}

Keywords: Staphylococci, MALDI, non-hospital, antibiotic resistance, environment

Drug-resistant staphylococci have been a growing threat to the community and hospitals due to the misuse of antibiotics by humans, industrialization and lack of novel antimicrobials currently available. Staphylococcus aureus and coagulase-negative staphylococci (CoNS) are major contaminants of touch surfaces; they are pervasive in both clinical and non-clinical surfaces [1]. The transmission of staphylococci, including methicillin-resistant strains, occurs primarily via direct contact with these contaminated surfaces. The ability for staphylococci to survive for long periods of time on surfaces in public areas, where they frequently come into contact with people, can facilitate their easy transmission from person to person. The most well studied member of this genus is methicillin resistant Staphylococcus aureus (MRSA), a common hospital and environmental pathogen. It is now clear that there is a high number of Staphylococcus

\section{*Corresponding author}

Tel: +61-7-5552-7709, Fax: +61-7-5678-0163

E-mail: a.idris@griffith.edu.au

○ 2017, The Korean Society for Microbiology and Biotechnology aureus and MRSA contamination in non-hospital environments [2]. There is a growing evidence to indicate an increase in the presence of drug-resistant staphylococci outside of the nosocomial and healthcare setting. There have been only a handful of studies investigating the incidence of multiple drug resistant staphylococci from non-healthcare environments including hotels [3], public restrooms [4, 5], public transport places [6-10], water parks [11], public telephones [12] and fitness centers [1315]. However, the presence of drug resistant staphylococci has not been investigated in public library spaces. This study aims to investigate the presence of staphylococci in public libraries in the East London area to assess the level of antibiotic resistance in these bacteria. Seven different staphylococcal species were identified by Matrix -assisted laser desorption/ionization time of flight mass spectrometry (MALDI-TOF-MS) analysis. Out of the thirty-four staphylococci isolates, nine were resistant to multiple antibiotics including seven isolates which were oxacillin resistant. This short study provides evidence of the presence of multidrug-resistant staphylococci in 
public libraries in the East London area.

Dry sterile cotton swabs (Copan Diagnostics Inc, CA) were used to collect samples from selected book surfaces in public libraries in the East London area, United Kingdom. Approximately $4 \mathrm{~cm}^{2}$ areas were sampled using dry cotton swab and stored in sterile swab collection tubes. A total of 100 swabs were collected. All specimens were transferred to the laboratory within 1-3 hours of the sample being taken. In the laboratory, the swabs were plated onto Nutrient Agar (Nutrient Agar, Oxoid, UK) medium before swabbing on to Mannitol Salt Agar (MSA, Oxoid, UK) selective medium to select for Gram-positive cocci. Plates were incubated for up to $48 \mathrm{~h}$ at $37^{\circ} \mathrm{C}$ [16]. Bacterial colonies growing on MSA is then sub-cultured onto another MSA plate to ensure purity of the colonies.

Bacterial isolates were identified using MALDI-TOFMS. Colonies (3-5) of overnight cultures were suspended in $300 \mu \mathrm{l}$ distilled water. The suspension was mixed with $100 \%$ absolute ethanol and centrifuged for $1 \mathrm{~min}$ at $13,000 \times g$. The pellets were re-suspended in $25 \mu \mathrm{l}$ of $70 \%$ formic acid and then $25 \mu \mathrm{l}$ pure acetonitrile was added. After mixing, solutions were centrifuged at $13,000 \times g$ for $2 \mathrm{~min}$. One $\mathrm{ml}$ aliquots of the supernatant were spotted in duplicate onto MALDI ground steel targets, air-dried for 5 min at room temperature and each target spot was then overlaid with $1 \mu \mathrm{l}$ a-cyano-4-hydroxycinnamic (HCCA) matrix solution. All isolates were purified and analyzed by MALDI-TOF-MS (Microflex LT, MALDITOF-MS, Bruker Daltonics, UK) in a positive linear mode (2000 to $20000 \mathrm{~m} / \mathrm{z}$ range). The resulting spectra for each culture was analysed by MALDI-Biotyper 2.0 software (Bruker Daltonics, UK). The software evaluates each spectra compared to a reference spectra in the Bruker Taxonomy Database identifying the best match from database records. Results were expressed as scores (QI) from 0 to 3, as recommended by the manufacturer. Scores QI $\leq 1.7$ were not considered as reliable identification. A score of $\mathrm{QI} \geq 1.7$ corresponded to 'genus' identification. Only scores higher than QI $\geq 2$ were considered a reliable identification of species.

Strains were then screened for resistance to antibiotics by agar disk diffusion on Iso Sensitest media (Iso Sensitest Agar, Oxoid, UK). Zones of inhibition were evaluated against twelve antibiotics (Oxoid, UK). The following antibiotic discs were used; chloramphenicol $(30 \mu \mathrm{g})$, erythromycin (15 $\mu \mathrm{g})$, fusidic acid (10 $\mu \mathrm{g})$, oxacillin (1 $\mu \mathrm{g})$, streptomycin $(10 \mu \mathrm{g})$, tetracycline $(10 \mu \mathrm{g})$, cefoxitin $(30 \mu \mathrm{g})$, gentamicin $(10 \mu \mathrm{g})$, vancomycin $(5 \mu \mathrm{g})$, cefepime $(30 \mu \mathrm{g})$, amoxicillin $(10 \mu \mathrm{g})$ and mupirocin $(20 \mu \mathrm{g})$. The minimum inhibitory concentrations (MICs) to oxacillin were additionally evaluated using "M.I.C. evaluators", antimicrobial gradient strips designed for accurate Minimum Inhibitory Concentration (MIC) values (Oxoid Ltd., UK). The categories susceptible, intermediate resistant or resistant were assigned on the basis of the CLSI antimicrobial susceptibility testing standards.

To determine the presence of the mecA gene, PCR amplification of the gene was performed. Fresh overnight cultures were centrifuged at $2 \mathrm{~min}$ at $4,000 \times g$ before decanting the supernatant. To extract DNA, bacterial pellets were then resuspended in $20 \mu \mathrm{l}$ of sterile $\mathrm{H}_{2} \mathrm{O}$ and subjected to warming at $100^{\circ} \mathrm{C}$ for $10 \mathrm{~min}$ before cooling down at room temperature. The presence of the mecA gene was determined using primers described previously [5]. PCR thermal cycling conditions were 2 min at $94^{\circ} \mathrm{C}$, 35 cycles for $30 \mathrm{~s}$ at $94^{\circ} \mathrm{C}, 30 \mathrm{~s}$ for $59^{\circ} \mathrm{C}$ and $1 \mathrm{~min}$ for $72^{\circ} \mathrm{C}$. The 2 log DNA ladder I (New England Biolab, UK) was used as molecular size markers.

94 out of the 113 isolates (83.7\%) were identified using MALDI-TOF-MS (Table 1). The remaining 19 isolates (16.3\%) failed to give a reliable identification. The rates of MALDI-TOF identification at the species level with a score of QI $\geq 2$ were $89.4 \%$ (84/94) and at genus level with a score of $1.7 \leq \mathrm{QI} \leq 2$ were $10.6 \%$ (10/94). In this study, a large number of staphylococci were recovered from our samples. Overall, we identified 34 staphylococcal isolates belonging to 7 species. This included Staphylococcus warneri $(n=6)$, Staphylococcus haemolyticus $(n=11)$, Staphylococcus hominis $(n=1)$, Staphylococcus

Table 1. Summary of Family and Genera of bacteria identified by MALDI-TOF-MS.

\begin{tabular}{llc}
\hline \multicolumn{1}{c}{ Family } & \multicolumn{1}{c}{ Genus } & No of isolates \\
\hline Staphylococcaceae & Staphylococcus & 34 \\
Dermabacteraceae & Brachybacterium & 1 \\
Micrococcaceae & Micrococcus & 53 \\
Micrococcaceae & Kocuria & 3 \\
Corynebacteriaceae & Corynebacterium & 2 \\
Intrasporangiaceae & Kytococcus & 1 \\
\hline \multicolumn{1}{c}{ Total } & & 94 \\
\hline
\end{tabular}


saprophyticus $(n=2)$, Staphylococcus capitis $(n=3)$, Staphylococcus cohnii $(n=2)$ and Staphylococcus epidermidis $(n=9)$. We also identified several other bacteria such as, brachybacterium, micrococcus, corynebacterium, kocuria and kytococcus. Our findings highlight the complexity of the number of bacterial types that can be found on human contact surfaces on public library books but staphylococci were the most common.

Most of the staphylococci isolated in our study carried antibiotic determinants. All of the staphylococci isolates in this study were antibiotic resistant (Table 2). Nine of the isolates were resistant to five or more antibiotics out of which seven isolates were resistant to oxacillin including Staphylococcus haemolyticus (\#7, \#14) and Staphylococcus epidermidis (\#23, \#25, \#26, \#27) (Table 2). Methicillin resistance is commonly associated with the carriage of the mecA gene, which encodes penicillin binding protein, PBP2a. Our results also showed that seven

Table 2. Resistance profiles and molecular characterization of antibiotic resistant staphylococci isolated from book surfaces in public libraries in the East London area, United Kingdom.

\begin{tabular}{|c|c|c|c|c|c|c|c|c|c|c|c|c|c|c|c|}
\hline$\#$ & Species & $\mathrm{n}$ & 0 & $\mathrm{~V}$ & $M$ & $\mathrm{Cp}$ & G & Fc & $S$ & $A$ & $E$ & $\mathrm{~T}$ & $C$ & $\mathrm{Cf}$ & MecA \\
\hline 1 & S. haemolyticus & 1 & & $\mathrm{R}$ & & & $\mathrm{R}$ & & $\mathrm{R}$ & & & & & $\mathrm{R}$ & \\
\hline 2 & S. warneri & 3 & & $\mathrm{R}$ & & & & & $\mathrm{R}$ & & & & & & \\
\hline 3 & S. epidermidis & 1 & & & & & & & $\mathrm{R}$ & $\mathrm{R}$ & & & & & \\
\hline 4 & S. warneri & 1 & & $\mathrm{R}$ & & & & $\mathrm{R}$ & $\mathrm{R}$ & & $\mathrm{R}$ & $\mathrm{R}$ & & & \\
\hline 5 & S. cohnii & 1 & & $\mathrm{R}$ & & & & $\mathrm{R}$ & $\mathrm{R}$ & & $\mathrm{R}$ & & & & \\
\hline 6 & S. haemolyticus & 1 & & & & & & & $\mathrm{R}$ & & & & & & \\
\hline 7 & S. haemolyticus & 1 & $\mathrm{R}$ & $\mathrm{R}$ & & & & $\mathrm{R}$ & $\mathrm{R}$ & & $\mathrm{R}$ & & & & + \\
\hline 8 & S. saprophyticus & 1 & & $\mathrm{R}$ & & & & $\mathrm{R}$ & $\mathrm{R}$ & & & & & & \\
\hline 9 & S. captis & 2 & & $\mathrm{R}$ & & & & & $\mathrm{R}$ & & & & & & \\
\hline 10 & S. epidermidis & 1 & & $\mathrm{R}$ & $\mathrm{R}$ & $\mathrm{R}$ & & & $\mathrm{R}$ & $\mathrm{R}$ & & & & & \\
\hline 11 & S. warneri & 1 & & $\mathrm{R}$ & $\mathrm{R}$ & & & & $\mathrm{R}$ & & & & & & \\
\hline 12 & S. warneri & 1 & & $\mathrm{R}$ & & & & & $\mathrm{R}$ & $\mathrm{R}$ & & & & & \\
\hline 13 & S. haemolyticus & 1 & & $\mathrm{R}$ & $\mathrm{R}$ & & & $\mathrm{R}$ & $\mathrm{R}$ & & & & & & \\
\hline 14 & S. haemolyticus & 2 & $\mathrm{R}$ & $\mathrm{R}$ & & & & & $\mathrm{R}$ & $\mathrm{R}$ & & & & $\mathrm{R}$ & + \\
\hline 15 & S. haemolyticus & 2 & & $\mathrm{R}$ & & & & & $\mathrm{R}$ & & & & & & \\
\hline 16 & S. haemolyticus & 2 & & $\mathrm{R}$ & & & & $\mathrm{R}$ & $\mathrm{R}$ & & & & $\mathrm{R}$ & & \\
\hline 17 & S. saprophyticus & 1 & & & & & & $\mathrm{R}$ & & $\mathrm{R}$ & & $\mathrm{R}$ & & & \\
\hline 18 & S. hominis & 1 & & $\mathrm{R}$ & & & & & & & & & & & \\
\hline 19 & S. cohnii & 1 & & & & & & $\mathrm{R}$ & & & & & & & \\
\hline 20 & S. epidermidis & 1 & & $\mathrm{R}$ & & & & & $\mathrm{R}$ & $\mathrm{R}$ & $\mathrm{R}$ & & & & \\
\hline 21 & S. haemolyticus & 1 & & $\mathrm{R}$ & & & & & $\mathrm{R}$ & & & $\mathrm{R}$ & & & \\
\hline 22 & S. captis & 1 & & $\mathrm{R}$ & & & & & $\mathrm{R}$ & $\mathrm{R}$ & & & & & \\
\hline 23 & S. epidermidis & 1 & $\mathrm{R}$ & $\mathrm{R}$ & & & & $\mathrm{R}$ & $\mathrm{R}$ & $\mathrm{R}$ & $\mathrm{R}$ & $\mathrm{R}$ & & & + \\
\hline 24 & S. epidermidis & 1 & & & $\mathrm{R}$ & & & & $\mathrm{R}$ & & & & & & \\
\hline 25 & S. epidermidis & 1 & $\mathrm{R}$ & $\mathrm{R}$ & & & & $\mathrm{R}$ & $\mathrm{R}$ & $\mathrm{R}$ & $\mathrm{R}$ & $\mathrm{R}$ & & $\mathrm{R}$ & + \\
\hline 26 & S. epidermidis & 1 & $\mathrm{R}$ & & & & & $\mathrm{R}$ & $\mathrm{R}$ & $\mathrm{R}$ & $\mathrm{R}$ & $\mathrm{R}$ & & & + \\
\hline 27 & S. epidermidis & 1 & $\mathrm{R}$ & $\mathrm{R}$ & & & & $\mathrm{R}$ & & $\mathrm{R}$ & $\mathrm{R}$ & $\mathrm{R}$ & & $\mathrm{R}$ & + \\
\hline 28 & S. epidermidis & 1 & & & & & & & & & $\mathrm{R}$ & & & & \\
\hline
\end{tabular}

\#, Assigned numerical ID

$\mathrm{n}$, Similar isolates from each sampling location (i.e. library)

O: oxacillin; V: vancomycin; M: mupirocin; Cp: cefepime; G: gentamicin; Fc: fusidic acid; S: streptomycin; A: amoxicillin E: erythromycin; T: tetracycline; $\mathrm{C}$ : chloramphenicol; $\mathrm{Cf}$ : ciprofloxacin. 
of the oxacillin resistant staplylococci environmental isolates carried the mecA gene (Table 2). Our findings demonstrate that book covers from public libraries can indeed be a potential source of bacterial contamination. More importantly, our data provides evidence of the existence of multidrug resistant staphylococci in such public spaces. The presence of these bacteria in such environments provides further evidence that infection control measures, both in the hospitals and in public places, fails to limit the spread of multidrug resistant staphylococci and. This work represents an advance in biomedical science because this work has major implications in the issues of public health and safety outside of the healthcare setting hence emphasizing the importance of good hygiene in these environments.

\section{Acknowledgments}

Authors have no funding or support to report.

\section{Conflict of Interest}

Authors declare no conflict of interest.

\section{References}

1. Kassem II. 2011. Chinks in the armor: The role of the nonclinical environment in the transmission of Staphylococcus bacteria. Am. J. Infect. Control 39: 539-541.

2. Lin J, Lin D, Xu P, Zhang T, Ou Q, Bai C, et al. 2016. Non-hospital environment contamination with Staphylococcus aureus and methicillin-resistant Staphylococcus aureus: proportion metaanalysis and features of antibiotic resistance and molecular genetics. Environ. Res. 150: 528-540.

3. Xu Z, Mkrtchyan HV, Cutler RR. 2015. Antibiotic resistance and mecA characterization of coagulase-negative staphylococci isolated from three hotels in London, UK. Front. Microbiol. 6: 947.

4. Gibbons SM, Schwartz T, Fouquier J, Mitchell M, Sangwan N, Gil- bert JA, et al. 2015. Ecological succession and viability of humanassociated microbiota on restroom surfaces. Appl. Environ. Microbiol. 81: 765-773.

5. Mkrtchyan HV, Xu Z, Cutler RR. 2015. Diversity of SCCmec elements in Staphylococci isolated from public washrooms. BMC Microbiol. 15: 120.

6. Zhou F, Wang Y. 2013. Characteristics of antibiotic resistance of airborne Staphylococcus isolated from metro stations. Int. J. Environ. Res. Public Health 10: 2412-2426.

7. Yeh PJ, Simon DM, Millar JA, Alexander HF, Franklin D. 2011. A diversity of antibiotic-resistant Staphylococcus spp. in a public transportation system. Osong Public Health Res. Perspect. 2: 202209.

8. Otter JA, French GL. 2009. Bacterial contamination on touch surfaces in the public transport system and in public areas of a hospital in London. Lett. Appl. Microbiol. 49: 803-805.

9. Simões RR, Aires-de-Sousa M, Conceição T, Antunes F, da Costa PM, de Lencastre H. 2011. High prevalence of EMRSA-15 in Portuguese public buses: a worrisome finding. PLoS One 6: e17630.

10. Stepanović S, Cirković I, Djukić S, Vuković D, Svabić-Vlahović M. 2008. Public transport as a reservoir of methicillin-resistant staphylococci. Lett. Appl. Microbiol. 47: 339-341.

11. Davis TL, Standridge JH, Degnan AJ. 2009. Bacteriological analysis of indoor and outdoor water parks in Wisconsin. J. Water Health 7: 452-463.

12. Jerković-Mujkić A, Bescaron R, Memiscaron S. 2013. Bacterial contamination of public telephones in the downtown area of Sarajevo. African J. Microbiol. Res. 7: 1664-1667.

13. Mukherjee N, Dowd SE, Wise A, Kedia S, Vohra V, Banerjee P. 2014. Diversity of bacterial communities of fitness center surfaces in a U.S. metropolitan area. Int. J. Environ. Res. Public Health 11: $12544-12561$.

14. Markley JD, Edmond MB, Major Y, Bearman G, Stevens MP. 2012. Are gym surfaces reservoirs for Staphylococcus aureus? A point prevalence survey. Am. J. Infect. Control 40: 1008-1009.

15. Ryan KA, Ifantides $C$, Bucciarelli $C$, Saliba $H$, Tuli S, Black E, et al. 2011. Are gymnasium equipment surfaces a source of staphylococcal infections in the community? Am. J. Infect. Control 39: 148150.

16. Mkrtchyan HV, Russell CA, Wang N, Cutler RR. 2013. Could public restrooms be an environment for bacterial resistomes? PLoS One 8: e54223. 